\title{
Immune response-associated gene profiling in Japanese melanoma patients using multi-omics analysis
}

\author{
YASUTO AKIYAMA $^{1}$, YOSHIO KIYOHARA ${ }^{5}$, SHUSUKE YOSHIKAWA ${ }^{5}$, MASAKI OTSUKA ${ }^{5}$, \\ RYOTA KONDOU $^{1}$, CHIZU NONOMURA ${ }^{1}$, HARUO MIYATA ${ }^{1}$, AKIRA IIZUKA ${ }^{1}$, TADASHI ASHIZAWA ${ }^{1}$, \\ KEIICHI OHSHIMA ${ }^{2}$, KENICHI URAKAMI ${ }^{3}$, TAKESHI NAGASHIMA ${ }^{8}$, MASATOSHI KUSUHARA $^{4}$, \\ TAKASHI SUGINO $^{6}$ and $\mathrm{KEN} \mathrm{YAMAGUCHI}^{7}$
}

Divisions of ${ }^{1}$ Immunotherapy, ${ }^{2}$ Medical Genetics, ${ }^{3}$ Cancer Diagnostics Research and ${ }^{4}$ Regional Resources, Shizuoka Cancer Center Research Institute; Divisions of ${ }^{5}$ Dermatology, ${ }^{6}$ Pathology and ${ }^{7}$ Office of the President, Shizuoka Cancer Center Hospital, Shizuoka 411-8777; ${ }^{8}$ SRL Inc., Tokyo 191-0002, Japan

Received August 22, 2017; Accepted November 16, 2017

DOI: 10.3892/or.2017.6173

\begin{abstract}
Project High-tech Omics-based Patient Evaluation (HOPE), including comprehensive whole-exome sequencing (WES) and gene expression profiling (GEP) using freshly resected tumor specimens, has been in progress since its implementation in 2014. Among a total of 1,685 cancer patients, 13 melanoma patients were registered in the HOPE Project and were characterized using multi-omics analyses. Among the 13 melanoma patients, 4 were deceased, and 9 were alive. The mean overall survival (OS) and relapse-free survival (RFS) times of the melanoma patients were 16.9 and 14.7 months, respectively. Previously, we developed an immune response-associated gene list, which consisted of 164 genes in Project HOPE, for evaluating the immunological status. In the present study, the association of immune response-associated gene expression with immunological parameters, such as programmed death-ligand 1 (PD-L1) and CD8 expression levels, single nucleotide variant (SNV) number, and Vogelstein driver gene mutation number, was investigated. With respect to PD-L1 expression, both immuno-suppression and immuno-stimulation-related genes were upregulated in PD-L1-positive melanomas. In contrast, regarding Vogelstein driver mutations, several T-cell activation-related genes were
\end{abstract}

Correspondence to: Dr Yasuto Akiyama, Division of Immunotherapy, Shizuoka Cancer Center Research Institute, 1007 Shimonagakubo, Nagaizumi-cho, Sunto-gun, Shizuoka 411-8777, Japan

E-mail: y.akiyama@scchr.jp

Abbreviations: WES, whole-exome sequencing; GEP, gene expression profiling; PD-1, programmed death-1; PD-L1, programmed death-ligand 1; NGS, next-generation sequencing; SNV, single nucleotide variant; TIL, tumor-infiltrating lymphocyte; OS, overall survival; RFS, relapse-free survival

Key words: Japanese melanoma, whole-exome sequencing, gene expression profiling, overall survival, relapse-free survival significantly downregulated in the high driver gene mutation group. In addition, many T-cell activation-related genes were upregulated in the CD8-positive melanomas. The correlation of immune response-associated gene expression with the survival time of the melanoma patients was investigated. Eight specific genes were commonly identified as genes that were significantly correlated for both the overall OS and RFS time, which could be possible prognostic factors for melanoma patients. These results revealed that an immune response-associated gene panel could be an informative tool for evaluating the immunological status prior to clinical immunotherapy in the upcoming era of genomic cancer medicine.

\section{Introduction}

Programmed death-ligand 1 (PD-L1) and PD-1 expression is variably regulated in immune cells and tumor cells to maintain immunological tolerance, which controls the occurrence of an autoimmune reaction against self-antigens $(1,2)$. PD-L1-expressing antigen-presenting cells, such as monocytes, macrophages, dendritic and tumor cells regulate excess immune reactions and inhibit activated T-cell function $(3,4)$. Meanwhile, PD-1, the receptor for PD-L1, is expressed on activated T, B and NK cells in the tumor microenvironment. Anti-PD-1 blockade therapy promotes exhaustive marker-positive T-cell expansion and survival (5), resulting in an antitumor response in vivo.

Since the recent success of immune checkpoint antibodies, such as ipilimumab and nivolumab, as reported for metastatic melanoma patients, many ongoing clinical trials have been underway to evaluate their efficacy in various solid cancers other than melanomas (6-8). Despite these promising results, the response rate associated with the single antibody treatment is $\sim 20-40 \%$ while $60-70 \%$ of cancer patients belong to the non-responding group. Furthermore, it is still difficult to accurately predict the responders to antibody therapy based on the current preclinical studies $(9,10)$.

In the present study, we used a previously reported immune response-associated gene panel consisting of 164 genes (56 antigen-presenting cells and T-cell-associated genes, 
34 cytokine- and metabolism-associated genes, $47 \mathrm{TNF}$ and TNF receptor superfamily genes and 27 regulatory T-cell-associated genes) (11). The present study investigated the association of the gene panel expression with immunological and clinical parameters, such as i) PD-L1 expression; ii) a high mutation load [single nucleotide variant (SNV) number]; iii) a driver gene mutation; iv) CD8 expression; and v) survival time, using the genomic data from 13 melanoma patients in the Project High-tech Omics-based Patient Evaluation (HOPE). Since 2014, 1,685 cancer patients have been enrolled in Project HOPE in which the simultaneous analyses of whole-exome sequencing (WES) and gene expression profiling (GEP) have been performed $(12,13)$. We aimed to evaluate the immunological status in the tumor tissues using next-generation sequencing and to better obtain a prediction of the responders to immune checkpoint antibody treatment through suitable biomarker detection.

\section{Materials and methods}

Patient registration. Project HOPE uses comprehensive whole-exome sequencing and gene expression profiling of various tumor tissues and is conducted in accordance with the 'Ethical Guidelines for Human Genome and Genetic Analysis Research' in Japan. Informed consent was obtained from all the patients participating in Project HOPE, and the study was approved by the Institutional Review Board of Shizuoka Cancer Center (SCC), Japan. Tumor tissues, along with the surrounding normal tissues, were dissected from surgical specimens by trained pathologists. A total of 1,685 cancer patients were registered in Project HOPE from 2014 to 2015. Characteristics of the 13 melanoma patients listed are shown in Table I.

Comprehensive gene expression analysis using DNA microarray. Total RNA was extracted from $\sim 10 \mathrm{mg}$ of tissue samples using the miRNeasy Mini kit (Qiagen, Hilden, Germany) according to the manufacturer's instructions. The method of performing the DNA microarray analysis was previously described $(13,14)$. Briefly, the ratio of the expression intensity between the tumor tissue ( $\mathrm{T}$ ) and the surrounding normal tissue $(\mathrm{N})$ was calculated from the normalized values. The expression values for all probes were log (base 2) transformed before performing the statistical analysis.

Whole-exome sequencing (WES) analysis of the melanoma tissues using next-generation sequencing. WES analysis including mapping, variant calling and identification of somatic mutation were performed using the Ion Proton system with the Ion AmpliSeq ${ }^{\text {TM }}$ Exome kit, Torrent Suite Software and Ion Reporter ${ }^{\mathrm{TM}}$ Server system (Thermo Fisher Scientific, Waltham, MA USA) as previously reported (12). Briefly, all the variants called by the variant caller were available. However, the data presented in SCC represent those variants considered to be of good quality, based on the filtering in which the sequences were discarded with a quality $<30$, variant allele frequency $<10 \%$ or depth of coverage $<20$. Those mutations that were identified in tumor samples and not observed in matched normal samples were extracted as somatic mutations. Single-nucleotide variants (SNVs) of the total exonic mutations for each sequenced tumor included non-synonymous, synonymous, and indels/frameshift mutations. In the present study we focused on somatic SNVs. Additionally, Vogelstein driver gene mutation (15) profiling was investigated.

Immunohistochemistry. For the immune checkpoint protein staining, the anti-PD-L1 antibody (rabbit monoclonal, cat. 13684; 1:200 dilution) was purchased (Cell Signaling, Danvers, MA, USA). For the tumor-infiltrating lymphocyte (TIL) staining, anti-CD4 (mouse monoclonal, cat. MS-1528-S; 1:20 dilution) and anti-CD8 (mouse monoclonal, cat. MS-457-S; 1:50 dilution) antibodies (Thermo Fisher Scientific) were purchased and were used for the immunohistochemistry analysis. In each section stained with the various antibodies, 10 high-magnification (x200) fields were analyzed using WinROOF image-analyzing software (Mitani Corporation, Tokyo, Japan). The PD-L1 staining was evaluated as the percentage of tumor cells exhibiting positive membranous staining as follows: score $0,<1 \%$; score $1,1-5 \%$; score $2,>5-50 \%$; and score $3,>50 \%$ (16). The TIL level was assessed by a semiquantitative estimation of the density of the $\mathrm{CD} 8^{+} \mathrm{T}$ cells inside the tumor site as follows: score 0 , no or sporadic $\mathrm{CD} 8^{+} \mathrm{T}$ cells; score 1 , moderate number of $\mathrm{CD}^{+} \mathrm{T}$ cells; score 2 , abundant number of $\mathrm{CD}^{+} \mathrm{T}$ cells; and score 3 , highly abundant number of $\mathrm{CD} 8^{+} \mathrm{T}$ cells (17). The score that was most frequent in entire sections was assigned.

Statistical analysis. The differentially expressed genes derived from the 164 immune response-associated gene panels between the immunological parameter-positive and parameter-negative groups were identified using the volcano plot method. Each microarray probe was considered significantly differentially expressed between two groups of samples if they satisfied the following criteria: i) corrected t-test P-value $<0.05$; ii) a Benjamini-Hochberg false discovery rate (FDR) $<0.1$; and iii) a fold change $>2.0$ or below $1 / 2$. Correlations between the immune response-associated gene expression and the clinicopathological features, including the survival data, were analyzed using an unpaired two-tailed t-test or a Spearman coefficiency test. Values of $\mathrm{P}<0.05$ were considered significant. The relapse-free survival (RFS) was calculated from the date of the diagnosis until the date of distant relapse. The overall survival (OS) was calculated from the date of the diagnosis to the date of death from cancer. Follow-up was assessed from the date of the diagnosis to the last contact date with the event-free patients.

\section{Results}

PD-L1 and CD8 expression, Vogelstein driver genes mutations, and SNV number in melanoma tumors. PD-L1 expression was evaluated according to the criteria of the staining score, such that the scores of 1 and 2 were positive and a score of 0 was negative. Five cases were positive and 8 were negative for PD-L1 expression. According to the Vogelstein driver mutation number, the WES analysis revealed that 5 cases had $\geq 2$ mutations, and 8 had $<2$ mutations. For the SNV number, 4 cases had $\geq 100$ SNVs and 9 had $<100$. The CD8 expression level was high in 5 (scores 3 and 4) and low in 8 cases (scores 0-2) based on the IHC scoring denotations (Table I). 
Table I. Melanoma patient list registered in Project HOPE.

\begin{tabular}{|c|c|c|c|c|c|c|c|c|c|}
\hline Case & Age & Sex & Status & $\begin{array}{l}\text { Relapse-free } \\
\text { survival (M) }\end{array}$ & $\begin{array}{c}\text { Overall } \\
\text { survival }(\mathrm{M})\end{array}$ & PD-L1 ${ }^{\mathrm{b}}$ & $\begin{array}{l}\text { SNV no. } \\
\text { (exon) }\end{array}$ & $\begin{array}{l}\text { Vogelstein } \\
\text { mutation no. }\end{array}$ & $\mathrm{CD}^{\mathrm{b}}$ \\
\hline MEL-001 ${ }^{\mathrm{a}}$ & 69 & $\mathrm{~F}$ & Alive & 19 & 28 & 1 & 2712 & 12 & 2 \\
\hline MEL-002 & 79 & $\mathrm{~F}$ & Dead & - & - & 2 & 84 & 0 & 3 \\
\hline MEL-003 & 41 & $\mathrm{~F}$ & Alive & 24 & 24 & 0 & 15 & 0 & 2 \\
\hline MEL-004 & 50 & M & Alive & 22 & 22 & 1 & 35 & 1 & 4 \\
\hline MEL-005 & 60 & M & Alive & 22 & 22 & 0 & 31 & 0 & 1 \\
\hline MEL-006 & 31 & $\mathrm{~F}$ & Alive & 19 & 19 & 0 & 45 & 3 & 2 \\
\hline MEL-007 & 88 & $\mathrm{~F}$ & Dead & 4 & 8 & 1 & 737 & 8 & 3 \\
\hline MEL-008 & 78 & M & Alive & 19 & 19 & 0 & 88 & 1 & 4 \\
\hline MEL-009 & 81 & M & Alive & 17 & 17 & 0 & 30 & 0 & 1 \\
\hline MEL-010 & 85 & M & Dead & 5 & 16 & 1 & 297 & 3 & 1 \\
\hline MEL-011 & 58 & $\mathrm{~F}$ & Alive & 12 & 14 & 0 & 114 & 1 & 0 \\
\hline MEL-012 & 82 & $\mathrm{~F}$ & Dead & 3 & 4 & 0 & 69 & 2 & 3 \\
\hline MEL-013 & 58 & M & Alive & 10 & 10 & 0 & 39 & 0 & 2 \\
\hline
\end{tabular}

${ }^{\mathrm{a}}$ Metastatic lesion of the rib was used for analysis. ' Immunohistochemical stain. HOPE, High-tech Omics-based Patient Evaluation; SNV, single nucleotide variant; $F$, female; $M$, male.

Table II. Upregulated gene list in PD-L1-positive melanomas.

\begin{tabular}{|c|c|c|c|c|c|}
\hline Probe name & Gene symbol & $\mathrm{FC}$ & $\log \mathrm{FC}$ & Regulation & $\mathrm{P}$-value \\
\hline A_23_P412321 & CCR5 & 3.948 & 1.981 & Up & $1.99 \times 10^{-2}$ \\
\hline A_23_P69310 & CCRL2 & 5.753 & 2.524 & $\mathrm{Up}$ & $1.16 \times 10^{-2}$ \\
\hline A_23_P338479 & $\mathrm{CD} 274$ & 11.825 & 3.564 & $\mathrm{Up}$ & $1.60 \times 10^{-3}$ \\
\hline A_23_P15394 & CD68 & 3.930 & 1.975 & Up & $1.68 \times 10^{-2}$ \\
\hline A_24_P411561 & HAVCR2 & 2.953 & 1.562 & $\mathrm{Up}$ & $2.43 \times 10^{-2}$ \\
\hline A_32_P351968 & HLA-DMB & 3.057 & 1.612 & $\mathrm{Up}$ & $4.15 \times 10^{-2}$ \\
\hline A_23_P112026 & IDO1 & 9.284 & 3.215 & $\mathrm{Up}$ & $1.80 \times 10^{-4}$ \\
\hline A_23_P128919 & LGALS3 & 4.402 & 2.138 & Up & $2.58 \times 10^{-2}$ \\
\hline A_24_P372223 & MSR1 & 3.088 & 1.627 & Up & $2.53 \times 10^{-2}$ \\
\hline A_24_P274270 & STAT1 & 4.126 & 2.045 & Up & $3.31 \times 10^{-3}$ \\
\hline A_23_P49338 & TNFRSF12A & 12.512 & 3.645 & $\mathrm{Up}$ & $2.56 \times 10^{-2}$ \\
\hline A_23_P51936 & TNFRSF9 & 3.808 & 1.929 & $\mathrm{Up}$ & $3.06 \times 10^{-2}$ \\
\hline A_33_P3397763 & TNFSF9 & -5.673 & -2.504 & Down & $2.84 \times 10^{-2}$ \\
\hline
\end{tabular}

PD-L1, programmed death-ligand 1; FC, fold change.

Association of the immune response-associated gene expression with immunological parameters using a volcano plot. We previously established an immune response-associated gene panel, consisting of 164 genes (11). The association of the immune response-associated gene expression obtained by the GEP data from Project HOPE with PD-L1 expression, SNV number, Vogelstein driver gene mutation number and CD8 expression was investigated using a volcano plot analysis.

With regard to the PD-L1 expression, 12 immune response-associated genes were identified as upregulated genes in the PD-L1-positive melanomas, in which 6 genes were involved in T-cell suppression and 6 were related to
T-cell activation (Fig. 1A and Table II). In addition, the VEGF gene alone was identified as an upregulated gene in high SNV number with $>100$ melanomas (Fig. 1B). Regarding the Vogelstein driver mutation number, in contrast, 18 immune response-associated genes were downregulated in the Vogelstein mutation high-number group. Notably, 9 genes involved in T-cell activation, such as CD3 (D, G and Z), CD40LG, STAT4, CCL5, TNFRSF4, TNFSF8 and TNFSF14, were identified (Fig. 1C and Table III). Notably, 14 immune response-associated genes were identified as upregulated genes in the TIL marker CD8-high melanomas, which were mostly correlated to T-cell activation favoring a Th1 response leading to tumor killing by CTLs (Fig. 1D). 
A

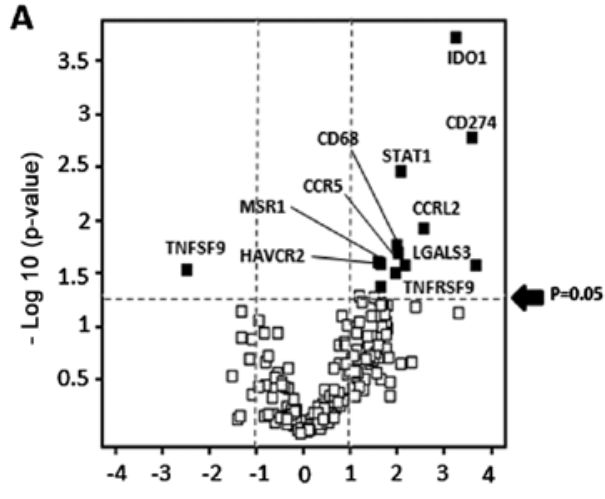

C

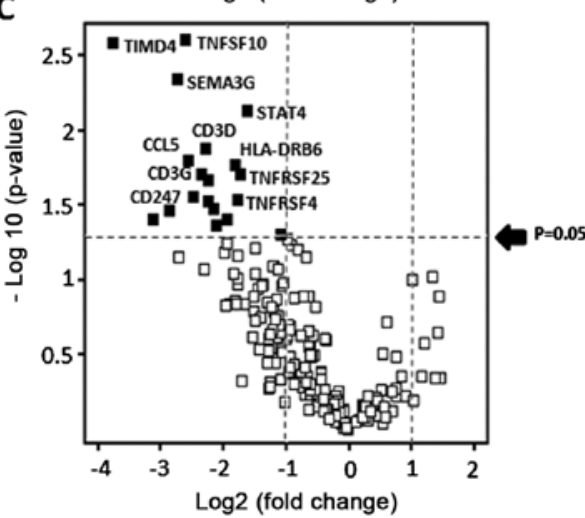

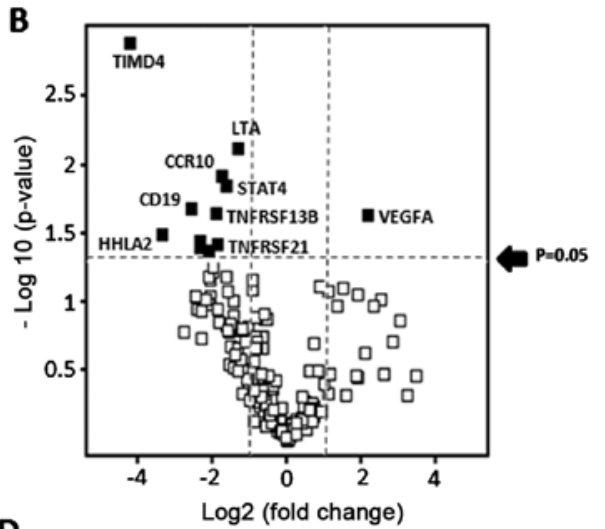

D

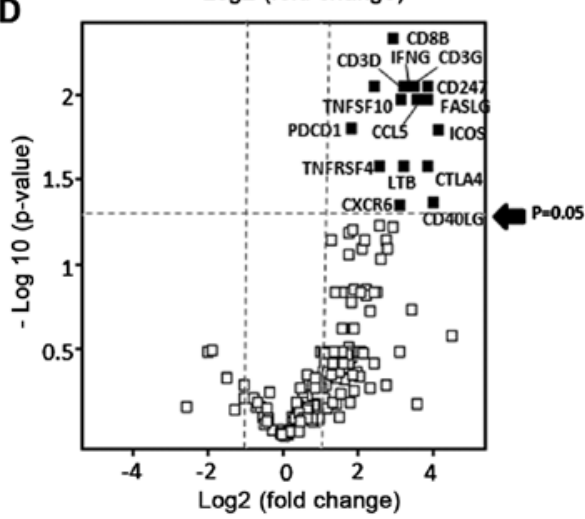

Figure 1. The association of the expression of the immune response-associated genes with PD-L1 expression, SNV number, Vogelstein driver gene mutation number and CD8 expression. The GEP data of a panel of 164 immune response-associated genes from 13 melanoma tumors were analyzed in terms of the association with various parameters using a volcano plot method. (A) PD-L1 expression. Five positive (IHC score $\geq 1$ ) and 8 negative (IHC score 0) cases (B) SNV number. Four positive (SNV no. $\geq 100)$ and 9 negative (SNV no. $<100)$ cases. (C) Vogelstein mutation number. Five positive (mutation no. $\geq 2)$ and 8 negative (mutation no. <2) cases. (D) CD8 expression. Five positive (IHC score 3-4) and 8 negative (IHC score 0-2) cases. The horizontal dashed line represented a P-value of 0.05 . The vertical dashed lines revealed 2- and 0.5 -fold changes in gene expression. The closed squares represented differentially altered genes in expression, with more than a 2-fold difference. PD-L1, programmed death-ligand 1; SNV, single nucleotide variant; GEP, gene expression profiling; IHC, immunohistochemistry.

Table III. Downregulated gene list in driver mutation high melanomas.

\begin{tabular}{|c|c|c|c|c|}
\hline Probe name & Gene symbol & $\mathrm{FC}$ & Regulation & P-value \\
\hline A_24_P63380 & BMPR1B & -4.37088 & Down & $4.24 \times 10^{-2}$ \\
\hline A_33_P3358923 & BTLA & -4.76685 & Down & $2.12 \times 10^{-2}$ \\
\hline A_23_P152838 & CCL5 & -5.93301 & Down & $1.55 \times 10^{-2}$ \\
\hline A_23_P34676 & CD247 (CD3 $\zeta)$ & -5.64369 & Down & $2.71 \times 10^{-2}$ \\
\hline A_33_P3375541 & CD3D & -4.90473 & Down & $1.29 \times 10^{-2}$ \\
\hline A_23_P98410 & CD3G & -5.11053 & Down & $1.91 \times 10^{-2}$ \\
\hline A_33_P3250680 & CD40LG & -7.29745 & Down & $3.38 \times 10^{-2}$ \\
\hline A_33_P3218980 & ENTPD1 & -3.87063 & Down & $3.87 \times 10^{-2}$ \\
\hline A_24_P169013 & HLA-DRB6 & -3.53737 & Down & $1.66 \times 10^{-2}$ \\
\hline A_33_P3248265 & LTB & -4.80739 & Down & $2.93 \times 10^{-2}$ \\
\hline A_23_P6818 & SEMA3G & -6.73986 & Down & $4.43 \times 10^{-3}$ \\
\hline A_23_P68031 & STAT4 & -3.11526 & Down & $7.24 \times 10^{-3}$ \\
\hline A_23_P7503 & TIMD4 & -13.6631 & Down & $2.52 \times 10^{-3}$ \\
\hline A_33_P3234530 & TNFRSF25 & -3.34808 & Down & $1.91 \times 10^{-2}$ \\
\hline A_33_P3286157 & TNFRSF4 & -3.47391 & Down & $2.84 \times 10^{-2}$ \\
\hline A_23_P121253 & TNFSF10 & -4.52915 & Down & $3.28 \times 10^{-2}$ \\
\hline A_21_P0000113 & TNFSF10 & -6.11132 & Down & $2.40 \times 10^{-3}$ \\
\hline A_24_P237036 & TNFSF14 & -8.744 & Down & $3.86 \times 10^{-2}$ \\
\hline A_23_P169257 & TNFSF8 & -2.1605 & Down & $4.88 \times 10^{-2}$ \\
\hline
\end{tabular}

Bold indicates activated T-cell-associated genes. FC, fold change. 
Table IV. Correlation of immune response-associated genes with survival time.

\begin{tabular}{lcc}
\hline & Overall survival & \\
\hline Gene name & r-value & P-value \\
\hline CCR6 & 0.6829 & 0.0295 \\
CD27 & 0.7561 & 0.0114 \\
CDH3 & 0.7744 & 0.0085 \\
CXCR6 & 0.7561 & 0.0114 \\
IL17RB & 0.6646 & 0.0036 \\
PDCD1 & 0.6525 & 0.0409 \\
TNFRSF11A & 0.9147 & 0.0002 \\
ADAM12 & -0.8721 & 0.0011 \\
EDA2R & -0.8598 & 0.0014 \\
GREB1 & -0.7073 & 0.0221 \\
IL6 & -0.6829 & 0.0295 \\
STAT5A & -0.7622 & 0.0014 \\
TDO2 & -0.6342 & 0.0489 \\
TREM1 & -0.7012 & 0.0239 \\
\hline
\end{tabular}

\begin{tabular}{lcc}
\multicolumn{3}{c}{ Relapse-free survival } \\
\hline Gene name & r-value & P-value \\
\hline BTLA & 0.7078 & 0.0221 \\
B7H5 & 0.6585 & 0.0384 \\
B7H7 & 0.7632 & 0.0102 \\
CD27 & 0.8493 & 0.0019 \\
CD3E & 0.6893 & 0.0274 \\
CD8B & 0.7816 & 0.0076 \\
CXCR6 & 0.8555 & 0.0016 \\
FASLG & 0.6401 & 0.0462 \\
IL17RB & 0.7571 & 0.0112 \\
LAG3 & 0.7447 & 0.0135 \\
PDCD1 & 0.7936 & 0.0061 \\
TIMD4 & 0.7509 & 0.0123 \\
TNFRSF11A & 0.7755 & 0.0084 \\
TNFRSF21 & 0.6647 & 0.0362 \\
ADAM12 & -0.7385 & 0.0147 \\
EDA2R & -0.7016 & 0.0237 \\
TREM1 & -0.6524 & 0.0409
\end{tabular}

Bold indicates common genes in both overall and relapse-free survival.

Correlation of the immune response-associated gene expression with the survival time of the melanoma patients. The correlation of the expression of 164 immune response-associated genes with the overall and relapse-free survival time was investigated using a Spearman's rank-order correlation. Fourteen genes and 17 genes were significantly correlated with the overall and relapse-free survival time, respectively (Table IV). Eight genes, including CD27, CXCR6, IL17RB, PDCD1, TNFRSF11A, ADAM12, EDA2R and TREM1, were commonly identified in both the overall and relapse-free survival time groups, and 5 were positively correlated and 3 were negatively correlated.

\section{Discussion}

In the present study, we used a previously reported immune response-associated gene panel that consisted of 164 genes (11), and investigated the association of the expression of the gene panel with immunological and clinical parameters, such as: i) PD-L1 expression; ii) a high mutation load [single nucleotide variant (SNV) number]; iii) driver gene mutation; iv) CD8 expression; and v) survival time, using the genomic data from 13 melanoma patients registered in Project HOPE.

With advances in cancer genomic sequencing, specific gene signatures involved in the therapeutic response and prognosis have been reported, and their accuracy and efficiency have been investigated in various types of cancer, such as breast, stomach, non-small cell lung cancers and melanomas $(18,19)$. However, few studies focusing on immune-related gene panels or signature identifications have been reported since the development of cancer genomic technologies such as next-generation sequencing. The identification of cancer-specific T-cell receptor (TCR) sequences has been attempted in immunological routine analyses (20), but not much success has been obtained. Small scale genetic studies focusing on renal cell cancer or polypoid precancerous colorectal lesions revealed that tumor-associated macrophage markers or TIL markers were involved in the prognosis or the progression of precancerous to cancerous lesions $(21,22)$. However, Lee et al (23) obtained biopsy tissues from 55 triple-negative breast cancer patients treated with combined chemotherapy, and evaluated immune responses using the NanoString nCounter GX human immunology panel (579 immune-related genes), which demonstrated that a higher expression of cytotoxic molecules, TCR signaling pathway molecules, Th1 cytokines and B cell markers were associated with a pathological complete response (CR).

First, the association of the immune response-associated gene panel expression with the expression level of PD-L1 was investigated in the present study. Twelve immune response-associated genes were identified as upregulated in the PD-L1-positive melanomas; 6 of these genes were involved in T-cell suppression and 6 were related to T-cell activation. In particular, the 6 T-cell stimulation-related genes were: CCRL2 (attraction of TILs) (24); CD68 (M1 macrophage activation); CCR5 (T-cell migration); HLA-DMB (increase of CD8 ${ }^{+}$TIL and IFN- $\gamma$ level, and improvement of survival) (25); STAT1 (IFN- $\gamma$ signal activation in T cells) (26) and TNFRSF9 (T-cell activation) (27). However, the others were T-cell inhibition-related genes, including; CD274 (PD-L1), IDO-1, HAVCR2 (TIM-3), LGALS3 (galectin-3), MSR1 and TNFRSF12A. Taube et al (28) reported similar results using a volcano plot of 11 melanoma patients, which demonstrated 12 upregulated genes in PD-L1-positive melanomas including 4 immuno-regulatory genes, such as CD274, PDCD1 (PD-1), LAG3 and IL-10. The upregulated gene profile in the PD-L1-positive melanomas in our study was similar to their analysis.

Second, the association of the immune response-associated gene panel expression with Vogelstein driver mutation number was investigated. Eighteen immune response-associated genes were downregulated in the Vogelstein mutation high-number $(>2)$ group. Notably, 9 genes involved in T-cell activation, including CD3 (D, G and Z), CD40LG, STAT4, CCL5, TNFRSF4, TNFSF8 
and TNFSF14, were identified. Among these, TNFRSF4 (OX40), TNFSF8 (CD30-L) and TNFSE14 (HVEM-L) are TNF ligand superfamily members and trigger T-cell stimulating signals by binding to their specific receptors. A constitutive signal activation, such as MAPK, STAT3, NF- $\mathrm{BB}$, and $\beta$-catenin, in cancer cells induces an immunosuppressive effect that is mediated by the TGF- $\beta$, IL- 6 , IL-10 and VEGF produced by the cancer cells, resulting in regulatory T-cell and myeloid derived suppressor cell (MDSC) induction (29). Specifically, an STK11 mutation and RAS/MAPK activation were linked to CD3 gene downregulation or a TIL reduction in the tumor $(30,31)$ Additionally, Frederick et al (32) demonstrated that a BRAF inhibition was associated with an upregulation of melanoma antigen expression and a favorable tumor microenvironment through the reduction of immunosuppressive cytokines, such as IL-6 and IL-8. In the present study, an extensive immunosuppressive effect on the T-cell activation signal was ascertained, but the upregulation of melanoma antigens was not significant because of the small number of cases in the evaluation.

Third, the correlation of the expression of 164 immune response-associated genes with the overall and relapse-free survival time was investigated using a Spearman's rank-order correlation. Eventually, 8 genes, such as CD27, CXCR6, IL17RB, PDCD1, TNFRSF11A, ADAM12, EDA2R and TREM1, were commonly identified in both the overall and relapse-free survival time groups, of which 5 were positively correlated and 3 were negatively correlated. Briefly, the survival-correlated gene profiling was as follows: $\mathrm{CD} 27$ (expressed on CD8 ${ }^{+} \mathrm{TIL}$ was associated with a good prognosis) (33); CXCR6 (the CXCR6/CXCL16 axis in the tumor was associated with a TIL increase and a good prognosis) (34); IL17RB (a higher HOXB13-to-IL17RB ratio was linked to a worse outcome) (35); TNFRSF11A (RANK upregulation may be linked to mammary tumorigenesis in BRCA1-mutant carriers) (36); ADAM12 [an aggressive ovarian cancer marker was associated with a TGF- $\beta$ induced epithelial to mesenchymal transition (EMT)] (37); EDA2R (highly expressed in ovarian cancer and was associated with a poor prognosis); and TREM1 (induced a proinflammatory and protumor microenvironment and was associated with a poor prognosis) (38). Based on these observations, the protein expression of the 8 markers, using previously resected melanoma tissues, warrants future investigation, and the specific association of the protein expression with the survival data based on a Kaplan-Meier analysis should be precisely performed.

Finally, in the present study, we investigated the association of the expression of the immune response-associated gene panel with various parameters, mainly PD-L1 and CD8 expression, driver gene mutation and survival time, and several gene signatures involved in patient prognosis were identified. These results revealed that cancer genomic data may be associated with specific immunological gene signatures closely linked to the immunological status in the tumor microenvironment, which could contribute to the development of specific cancer immunotherapies for tailored medicine called precision immunotherapy (39).

\section{Acknowledgements}

The authors thank the staff at the Shizuoka Cancer Center Hospital for the clinical support and sample preparation.

\section{References}

1. Zhang B, Chikuma S, Hori S, Fagarasan S and Honjo T: Nonoverlapping roles of PD-1 and FoxP3 in maintaining immune tolerance in a novel autoimmune pancreatitis mouse model. Proc Natl Acad Sci USA 113: 8490-8495, 2016.

2. Wang J, Okazaki IM, Yoshida T, Chikuma S, Kato Y, Nakaki F, Hiai H, Honjo T and Okazaki T: PD-1 deficiency results in the development of fatal myocarditis in MRL mice. Int Immunol 22: 443-452, 2010

3. Heeren AM, Koster BD, Samuels S, Ferns DM, Chondronasiou D, Kenter GG, Jordanova ES and de Gruijl TD: High and interrelated rates of $\mathrm{PD}-\mathrm{L1}^{+} \mathrm{CD} 14^{+}$antigen-presenting cells and regulatory $\mathrm{T}$ cells mark the microenvironment of metastatic lymph nodes from patients with cervical cancer. Cancer Immunol Res 3: 48-58, 2015.

4. Yaguchi T and Kawakami Y: Cancer-induced heterogeneous immunosuppressive tumor microenvironments and their personalized modulation. Int Immunol 28: 393-399, 2016.

5. Fourcade J, Sun Z, Pagliano O, Chauvin JM, Sander C, Janjic B, Tarhini AA, Tawbi HA, Kirkwood JM, Moschos S, et al: PD-1 and Tim-3 regulate the expansion of tumor antigen-specific $\mathrm{CD} 8^{+} \mathrm{T}$ cells induced by melanoma vaccines. Cancer Res 74: 1045-1055, 2014.

6. Topalian SL, Hodi FS, Brahmer JR, Gettinger SN, Smith DC, McDermott DF, Powderly JD, Carvajal RD, Sosman JA, Atkins MB, et al: Safety, activity, and immune correlates of anti-PD-1 antibody in cancer. N Engl J Med 366: 2443-2454, 2012.

7. Weber JS, O'Day S, Urba W, Powderly J, Nichol G, Yellin M, Snively J and Hersh E: Phase I/II study of ipilimumab for patients with metastatic melanoma. J Clin Oncol 26: 5950-5956, 2008.

8. Wolchok JD, Kluger H, Callahan MK, Postow MA, Rizvi NA, Lesokhin AM, Segal NH, Ariyan CE, Gordon RA, Reed K, et al: Nivolumab plus ipilimumab in advanced melanoma. N Engl J Med 369: 122-133, 2013.

9. Okazaki T, Chikuma S, Iwai Y, Fagarasan S and Honjo T: A rheostat for immune responses: The unique properties of PD-1 and their advantages for clinical application. Nat Immunol 14: 1212-1218, 2013.

10. Weber JS, D'Angelo SP, Minor D, Hodi FS, Gutzmer R, Neyns B, Hoeller C, Khushalani NI, Miller WH Jr, Lao CD, et al: Nivolumab versus chemotherapy in patients with advanced melanoma who progressed after anti-CTLA-4 treatment (CheckMate 037): A randomised, controlled, open-label, phase 3 trial. Lancet Oncol 16: 375-384, 2015.

11. Akiyama Y, Kondou R, Iizuka A, Ohshima K, Urakami K, Nagashima T, Shimoda Y, Tanabe T, Ohnami S, Ohnami S, et al: Immune response-associated gene analysis of 1,000 cancer patients using whole-exome sequencing and gene expression profiling-Project HOPE. Biomed Res 37: 233-242, 2016.

12. Urakami K, Shimoda Y, Ohshima K, Nagashima T, Serizawa M, Tanabe T, Saito J, Usui T, Watanabe Y, Naruoka A, et al: Next generation sequencing approach for detecting 491 fusion genes from human cancer. Biomed Res 37: 51-62, 2016.

13. Yamaguchi K, Urakami K, Ohshima K, Mochizuki T, Akiyama Y, Uesaka K, Nakajima T, Takahashi M, Tamai S and Kusuhara M: Implementation of individualized medicine for cancer patients by multiomics-based analyses-the Project HOPE-. Biomed Res 35: 407-412, 2014.

14. Ohshima K, Hatakeyama K, Nagashima T, Watanabe Y, Kanto K, Doi Y, Ide T, Shimoda Y, Tanabe T, Ohnami S, et al: Integrated analysis of gene expression and copy number identified potential cancer driver genes with amplification-dependent overexpression in 1,454 solid tumors. Sci Rep 7: 641, 2017.

15. Vogelstein B, Papadopoulos N, Velculescu VE, Zhou S, Diaz LA Jr and Kinzler KW: Cancer genome landscapes. Science 339: 1546-1558, 2013.

16. Garon EB, Rizvi NA, Hui R, Leighl N, Balmanoukian AS, Eder JP, Patnaik A, Aggarwal C, Gubens M, Horn L, et al; KEYNOTE-001 Investigators: Pembrolizumab for the treatment of non-small-cell lung cancer. N Engl J Med 372: 2018-2028, 2015.

17. Dahlin AM, Henriksson ML, Van Guelpen B, Stenling R, Oberg A, Rutegård J and Palmqvist R: Colorectal cancer prognosis depends on T-cell infiltration and molecular characteristics of the tumor. Mod Pathol 24: 671-682, 2011.

18. Hallett RM, Dvorkin-Gheva A, Bane A and Hassell JA: A gene signature for predicting outcome in patients with basal-like breast cancer. Sci Rep 2: 227, 2012. 
19. Cristescu R, Lee J, Nebozhyn M, Kim KM, Ting JC, Wong SS, Liu J, Yue YG, Wang J, Yu K, et al: Molecular analysis of gastric cancer identifies subtypes associated with distinct clinical outcomes. Nat Med 21: 449-456, 2015.

20. Munson DJ, Egelston CA, Chiotti KE, Parra ZE, Bruno TC, Moore BL, Nakano TA, Simons DL, Jimenez G, Yim JH, et al: Identification of shared TCR sequences from T cells in human breast cancer using emulsion RT-PCR. Proc Natl Acad Sci USA 113: 8272-8277, 2016.

21. Mickley A, Kovaleva O, Kzhyshkowska J and Gratchev A: Molecular and immunologic markers of kidney cancer-potential applications in predictive, preventive and personalized medicine. EPMA J 6: 20, 2015.

22. Maglietta A, Maglietta R, Staiano T, Bertoni R, Ancona N, Marra G and Resta L: The immune landscapes of polypoid and nonpolypoid precancerous colorectal lesions. PLoS One 11: e0159373, 2016.

23. Lee HJ, Lee JJ, Song IH, Park IA, Kang J, Yu JH, Ahn JH and Gong G: Prognostic and predictive value of NanoString-based immune-related gene signatures in a neoadjuvant setting of triple-negative breast cancer: Relationship to tumor-infiltrating lymphocytes. Breast Cancer Res Treat 151: 619-627, 2015.

24. Wang LP, Cao J, Zhang J, Wang BY, Hu XC, Shao ZM, Wang ZH and Ou ZL: The human chemokine receptor CCRL2 suppresses chemotaxis and invasion by blocking CCL2-induced phosphorylation of p38 MAPK in human breast cancer cells. Med Oncol 32: 254, 2015.

25. Callahan MJ, Nagymanyoki Z, Bonome T, Johnson ME, Litkouhi B, Sullivan EH, Hirsch MS, Matulonis UA, Liu J, Birrer MJ, et al: Increased HLA-DMB expression in the tumor epithelium is associated with increased CTL infiltration and improved prognosis in advanced-stage serous ovarian cancer. Clin Cancer Res 14: 7667-7673, 2008.

26. Avalle L, Pensa S, Regis G, Novelli F and Poli V: STAT1 and STAT3 in tumorigenesis: A matter of balance. JAK-STAT 1 65-72, 2012.

27. Nam KO, Kang WJ, Kwon BS, Kim SJ and Lee HW: The therapeutic potential of 4-1BB (CD137) in cancer. Curr Cancer Drug Targets 5: 357-363, 2005

28. Taube JM, Young GD, McMiller TL, Chen S, Salas JT, Pritchard TS, Xu H, Meeker AK, Fan J, Cheadle C, et al: Differential expression of immune-regulatory genes associated with PD-L1 display in melanoma: Implications for PD-1 pathway blockade. Clin Cancer Res 21: 3969-3976, 2015.

29. Kawakami Y, Yaguchi T, Sumimoto H, Kudo-Saito C Tsukamoto N, Iwata-Kajihara T, Nakamura S, Nishio H, Satomi R, Kobayashi A, et al: Roles of signaling pathways in cancer cells and immune cells in generation of immunosuppressive tumor-associated microenvironments. In: The Tumor Immunoenvironment. Shurin MR, Umansky V and Malyguine A (eds). Springer Science+Buisiness Media B.V., Dordrecht, The Netherlands, pp307-323, 2013.
30. Schabath MB, Welsh EA, Fulp WJ, Chen L, Teer JK, Thompson ZJ, Engel BE, Xie M, Berglund AE, Creelan BC, et al: Differential association of STK11 and TP53 with KRAS mutation-associated gene expression, proliferation and immune surveillance in lung adenocarcinoma. Oncogene 35: 3209-3216, 2016.

31. Loi S, Dushyanthen S, Beavis PA, Salgado R, Denkert C, Savas P, Combs S, Rimm DL, Giltnane JM, Estrada MV, et al: RAS/MAPK activation is associated with reduced tumor-infiltrating lymphocytes in triple-negative breast cancer: Therapeutic cooperation between MEK and PD-1/PD-L1 immune checkpoint inhibitors. Clin Cancer Res 22: 1499-1509, 2016.

32. Frederick DT, Piris A, Cogdill AP, Cooper ZA, Lezcano C Ferrone CR, Mitra D, Boni A,Newton LP, Liu C, et al: BRAF inhibition is associated with enhanced melanoma antigen expression and a move favorable tumor microenvironment in patients with metastatic melanoma. Clin Cancer Res 19: 1225-1231, 2013.

33. Wouters MC, Komdeur FL, Workel HH, Klip HG, Plat A, Kooi NM, Wisman GB, Mourits MJ, Arts HJ, Oonk MH, et al: Treatment regimen, surgical outcome, and T-cell differentiation influence prognostic benefit of tumor-infiltrating lymphocytes in high-grade serous ovarian cancer. Clin Cancer Res 22: 714-724, 2016.

34. Hojo S, Koizumi K, Tsuneyama K, Arita Y, Cui Z, Shinohara K, Minami T, Hashimoto I, Nakayama T, Sakurai H, et al: High-level expression of chemokine CXCL16 by tumor cells correlates with a good prognosis and increased tumor-infiltrating lymphocytes in colorectal cancer. Cancer Res 67: 4725-4731, 2007.

35. Zhao L, Zhu S, Gao Y and Wang Y: Two-gene expression ratio as predictor for breast cancer treated with tamoxifen: Evidence from meta-analysis. Tumour Biol 35: 3113-3117, 2014.

36. Nolan E, Vaillant F, Branstetter D, Pal B, Giner G, Whitehead L, Lok SW, Mann GB, Rohrbach K, Huang LY, et al; Kathleen Cuningham Foundation Consortium for Research into Familial Breast Cancer (kConFab): RANK ligand as a potential target for breast cancer prevention in BRCA1-mutation carriers. Nat Med 22: 933-939, 2016.

37. Cheon DJ, Li AJ, Beach JA, Walts AE, Tran H, Lester J, Karlan BY and Orsulic S: ADAM12 is a prognostic factor associated with an aggressive molecular subtype of high-grade serous ovarian carcinoma. Carcinogenesis 36: 739-747, 2015

38. Duan M, Wang ZC, Wang XY, Shi JY, Yang LX, Ding ZB, Gao Q, Zhou J and Fan J: TREM-1, an inflammatory modulator, is expressed in hepatocellular carcinoma cells and significantly promotes tumor progression. Ann Surg Oncol 22: 3121-3129, 2015.

39. Mandal R and Chan TA: Personalized oncology meets immunology: The path toward precision immunotherapy. Cancer Discov 6: 703-713, 2016. 